\title{
Discrimination and reproduction of patterns: Feature measures and constraint redundancy as predictors'
}

\author{
CYNTHIA M. MAVRIDES, MARY WASHINGTON COLLEGE \\ D. R. BROWN, 2 PURDUE UNIVERSITY
}

The statistical structure of samples of patterns /histoforms and polygons) was varied by manipulating constraint redundancy $\left(R_{c}\right)$ at three levels. Both $R_{c}$ and seven measures of pattern features were evaluated as predictors of reproduction errors and discrimination latency using multiple linear regression techniques. While it was possible to account for a significant proportion of performance variance from knowledge of $R_{c}$ levels, feature measures accounted for more performance variance under all conditions of testing. The results were interpreted as support for the notion that patterns are processed in terms of features.

There are limited physiological data (e.g., Hubel \& Wiesel, 1968) and accumulating psychophysical data (Aiken \& Brown, 1969a, b, c; Behrman \& Brown, 1968; Brown \& Andrews, 1968; Brown \& Brumaghim, 1968; Brumaghim \& Brown, 1968; Stenson, 1968; Sternberg, 1967) that support the conclusion that Os encode form in terms of specific features. For psychophysical purposes, then, we may view pattern as a complex attribute of objects or events that are multidimensional, the stimuli for the which the $O$ is sensitive. In Brunswikian terms, especially as elaborated by Beach $(1964 a, b)$ we may tentatively think of a pattern as being embedded in a multidimensional cue-dimension space where the cue dimensions are defined by the orderings of patterns with regard to their perceptually relevant features. Research problems of primary psychophysical interest include quantitatively specifying the nature of the features and specifying the rules by which information about the features is combined into a unitary response.

Elsewhere (Brown \& Owen, 1967), we have argued that the effective stimulus for visual form or pattern perception includes both properties of particular instances of stimulation (a form) and the properties of sets of forms (samples, populations, stimulus domains) of which particular instances are the elements. It is consistent with a broad range of perceptual theories to assume that the $O$ is sensitive to the statistical structure of the environment. If, in fact, form is processed in terms of a set of cue dimensions, then an appropriate analysis of the properties of the sample or stimulus domain is in terms of the distributions in the cue-dimension space. The studies reported here were designed to provide data in support of this conceptualization.

\section{Pattern Generation and Quantification}

In order to sample patterns in which it is possible to control the structure of samples in a specified feature, or cue-dimension space, the pattern generation procedure used by Evans and his co-workers (Evans \& Mueller, 1966) was combined with a feature-measurement approach we have previously used (e.g., Brown \& Owen, 1967). In particular, patterns were generated 3 using the VARGUS 9 pattern generation system with control of information and redundancy measures. Essentially, a prototype pattern is generated in histoform format with from 1 to 32 columns that range in height from three to seven units, and a sample of variant patterns is generated by adding a random variable (d) to the column heights. The nature of the sample of perception of which are the quantities of particular features to

variants is controlled by controlling the probability distribution of the random variable; and since it is unimodal and symmetrical, and since the random variable has a mean of zero, the prototype is the mean of all samples. As Evans (1967a) has pointed out, if appropriate identifications are made, three information measures may be calculated. Maximum channel capacity $\left(\mathrm{H}_{\max }\right)$, calculated in terms of bits per stimulus, occurs with random selection of column heights. Actual channel capacity $\left(\mathrm{H}_{\mathrm{a}}\right)$ is less than $H_{\max }$ when the probability distribution of $d$ is not rectangular; and the discrepancy between $\mathrm{H}_{\mathrm{max}}$ and $\mathrm{H}_{\mathrm{a}}$ may be quantified as constraint redundancy $\left(\mathbf{R}_{c}\right)$ :

$$
\mathbf{R}_{c}=1-\frac{\mathrm{H}_{\mathbf{a}}}{\mathrm{H}_{\max }} \times 100 .
$$

$\mathbf{R}_{\mathrm{c}}$ provides a measure of the extent to which a set of patterns deviates from the prototype and can be established in advance by the $\mathrm{E}$.

For these studies, a single eight-column prototype was used and three samples of 100,99 , and 99 variants were generated with 0,40 , and $70 \%$ constraint, respectively. Since our interest lay in a feature analysis quantification of the patterns, $R_{c}$ is not affected by the operations, and since computer programs are available for measuring features of polygons, the suggestion of
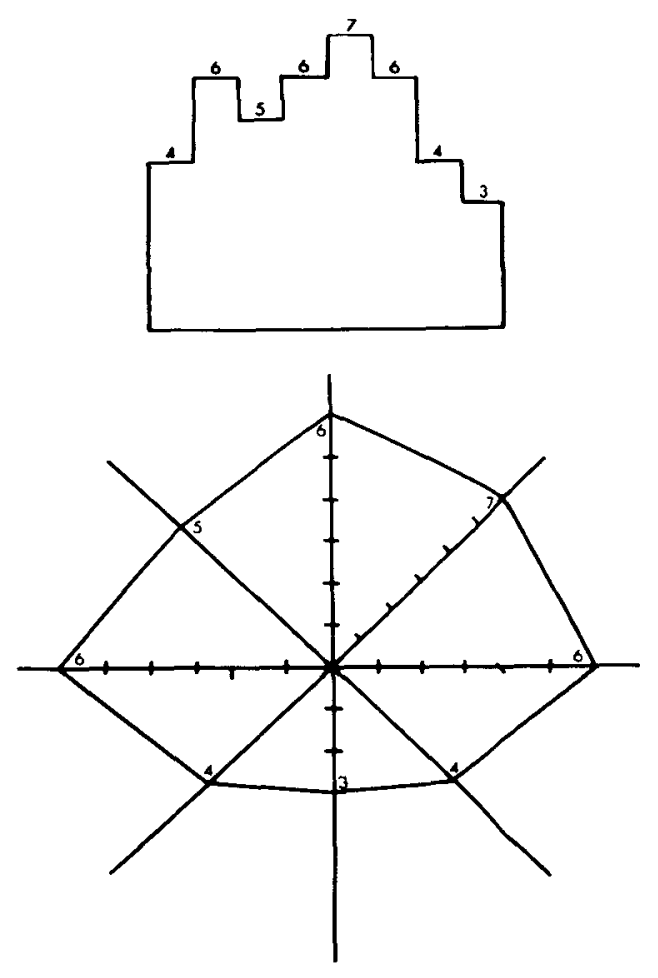

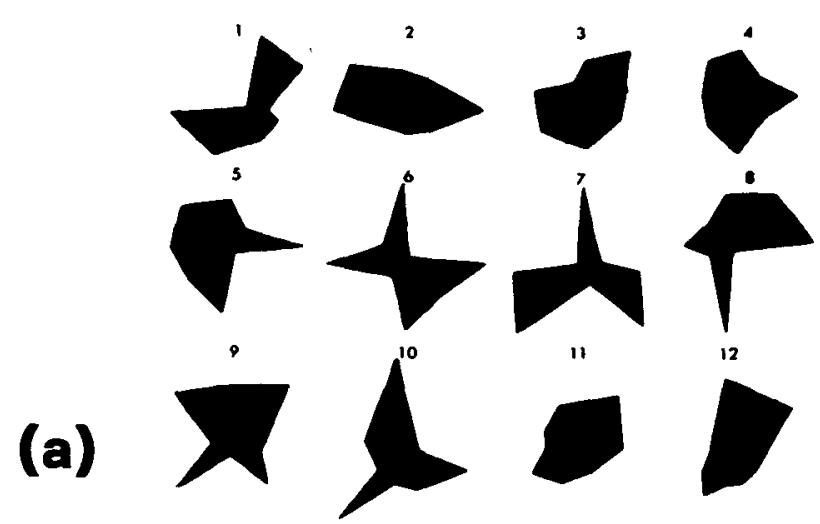

11
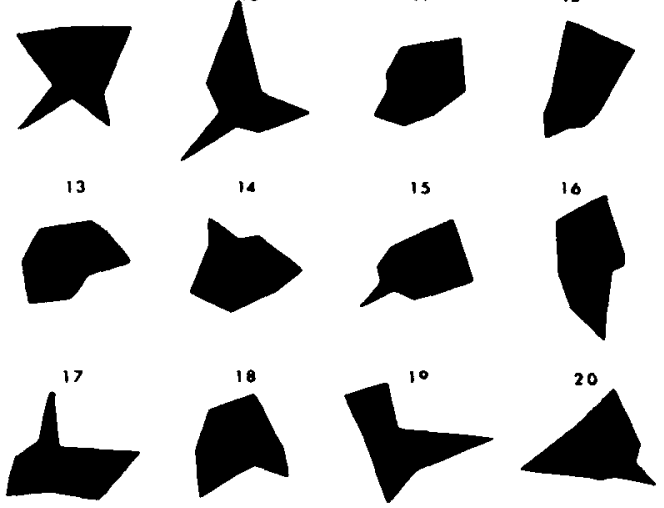

o* CONSTRaint (RANDOM)

Thurmond and Alluisi (1967) for transforming histoforms into polygons was used. This transformation, shown graphically for the prototype in Fig. 1, consists simply of mapping column heights of histoforms in the rectangular matrix in which they were generated, into radial lengths in a circular matrix. Following this operation, computer programs adjusted the area to a constant and 80 measures (Brown \& Owen, 1967) were computed from the coordinates in a 100 by 100 unit matrix. These patterns may be viewed as a subset of the stimulus domain of Type 1 random polygons (Attneave \& Arnoult, 1956) previously used, wherein we have found that a small subset of the 80 measures is perceptually relevant (e.g., Behrman \& Brown, 1967; Brown \& Andrews, 1967; Aiken \& Brown, 1969a, b, c; Forsyth \& Brown, $1967 \mathrm{a}, \mathrm{b})$. Accordingly, all subsequent analyses are based upon seven measures. ${ }^{4}$ If we view the measures as coordinate axes, the prototype polygon may be viewed as a point in a seven space and the three samples of patterns represent three clusters of points with the prototype as a common centroid.

\section{STUDY 1}

Evans (1967a, b) has argued from schema theory that increasing schematic redundancy should enhance performance in any task that requires memory of the whole pattern, since it is possible to retain the common properties of the set of patterns and increasing $R_{c}$ decreases variation from the prototype. This prediction has been supported for reproduction tasks where it was necessary to distinguish between random histoforms $\left(R_{c}=0 \%\right)$ and a schema $\left(R_{c}=67 \%\right)$ (Edmonds \& Evans, $1966 \mathrm{a}, \mathrm{b})$ and among schema (Edmonds \& Mueller, 1967). Study 1 was designed to evaluate this prediction for polygons, to relate performance to pattern features, and, incidentally, to compare performance on histoforms and polygons.

\section{Method}

Patterns. Three samples of 20 patterns each were selected at each level of $R_{c}$. Patterns were selected to match the larger
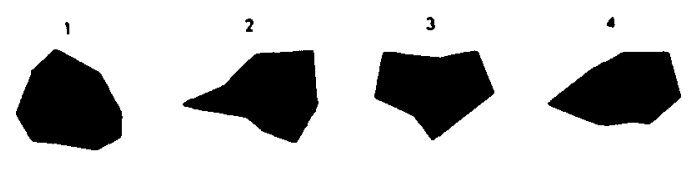

(b)
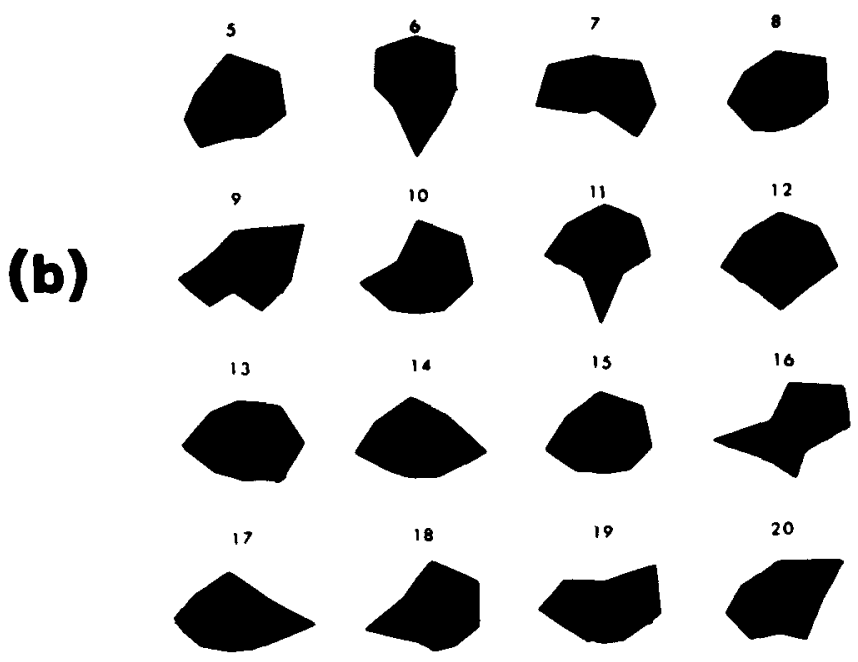

¿O* CONSTRAINT
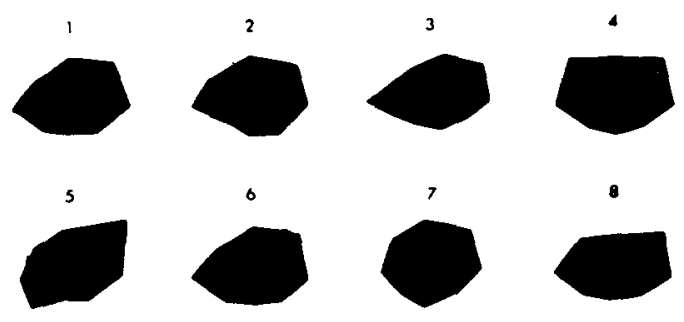

a

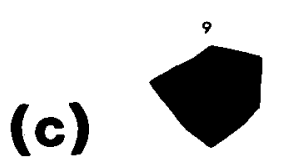

10
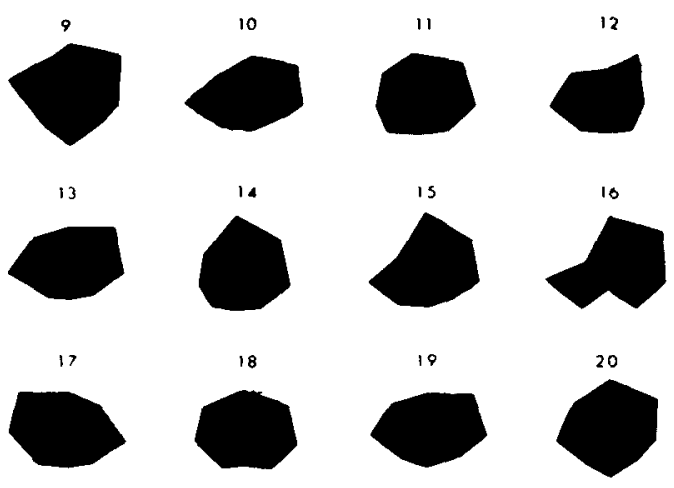

70\% CONSIRAINT

Fig. 2. Sample forms with $\mathbf{R}_{c}=0 \%$ (a), $40 \%$ (b), and $70 \%$ (c).

samples as nearly as possible in terms of the range and means of the six measures and the intercorrelations among the measures at each level of $R_{c}$. The polygon samples are shown in Figs. 2a-2c.

Subjects. Twenty-four introductory psychology students served as Ss.

Procedure and design. Three groups of eight Ss each were randomly assigned to the three $R_{c}$ levels and were tested in two 
Table 1

Mean Errors for Subjects in the Twelve Experimental Conditions

Administration

\begin{tabular}{ccccc} 
& & \multicolumn{2}{c}{1} & \multicolumn{2}{c}{2} \\
\cline { 5 - 5 } Constraint & Polygons & Histoforms & Polygons & Histoforms \\
\hline $0 \%$ & 13.38 & 14.37 & 11.13 & 13.38 \\
$40 \%$ & 17.63 & 20.63 & 14.50 & 15.88 \\
$70 \%$ & 29.25 & 34.13 & 26.38 & 28.63 \\
\hline
\end{tabular}

reproduction tasks (polygons and histoforms) in two complete administrations of the two tasks. Task sequence and the sequence of the 20 forms within tasks were both randomized for each group. The eight $\mathrm{Ss}$ in each group were tested as a group. On each trial, a pattern was projected from a random-access slide projector for $8 \mathrm{sec}$ and was followed by a 14-sec interval during which time Ss recorded their responses. Each polygon appeared, one to a page, in a response booklet with one point omitted and Ss were to record the missing point by picking one of the nine alternative lengths. The particular point that was omitted from each polygon was selected randomly. For histoforms, two column heights were deleted randomly and reproduction of both was required in the response booklet. Performance was assessed by computing the absolute deviation from the correct radial length or column height.

\section{Results}

Mean absolute errors are shown for all experimental conditions in Table 1. An analysis of variance of these data, assuming all factors were fixed, yielded no significant interactions. All main effects were, however, significant $(p \leqslant .01)$ with superior performance on polygons, superior performance on the second administration, and with the magnitude of reproduction errors inversely related to $R_{c}$. When the Newman-Keuls procedure (Winer, 1962, p. 80) was used to test differences among $R_{c}$ means, the reproduction of the random set was inferior to reproduction of both constrained sets $(p \leqslant .01)$ with no difference between the two levels of constraint. Since it is not known that the tasks were equivalent for polygons and histoforms, the fact that performance was superior on polygons is of minor concern. The fact that no other effects interacted with pattern format indicates, however, that the impact of constraint is general to both types of patterns and that practice effects were constant for both sets of patterns. The reliability coefficient computed between average errors over all 60 problems for the two administrations was .75 .

The major analyses were directed toward demonstrating that performance is related to the nature of the feature space in which patterns are embedded. Table 2 summarizes the impact of varying $R_{c}$ upon the feature space for the three samples of polygons. The correlation (point-biserial) between the levels of $\mathbf{R}_{c}$ and each of the measures and the means and variances of each measure for the three levels of $\mathbf{R}_{c}$ are given. The data in the table are redundant since the correlations simply reflect the differences in means for the measures over the $R_{c}$ levels. These data make it clear that manipulating $R_{c}$ results in changes in both means and variances for most measures.

Prediction of mean reproduction errors $\left(X_{0}\right)$ is presented in Table 3 where the results of several multiple linear regression analyses are summarized. In particular, the squares of the multiple correlations (per cent variance in $X_{0}$ which is linearly predictable) are given when only the levels of $\mathbf{R}_{c}$ are used as predictors $\left(\mathrm{r}_{0.1-3}^{2}\right)$ and prediction is over all 60 patterns, when only the seven feature measures are used and prediction is over all 60 patterns $\left(\mathrm{r}_{0.4-10}^{2}\right)$, and when both feature measures and $R_{c}$ were combined to predict over all 60 patterns $\left(\mathrm{r}_{0.1-10}^{2}\right)$. In addition, the feature measures were used as predictors over the 20 patterns within each $\mathbf{R}_{\mathbf{c}}$ level. Several points about these data are worth noting. That $\mathbf{R}_{c}$ levels predict performance variance simply reflects the fact that significant main effects were obtained in the analysis of variance due to $R_{c}$ and this result with polygons agrees with previous findings (e.g., Edmonds \& Evans, 1966a, b) that increasing $\boldsymbol{R}_{c}$ results in more accurate reproduction of histoforms. Of more interest here are several squared multiple semipartial correlations. The squared multiple semipartial correlation, $r_{0.1-10}^{2}-r_{0.4-10}^{2}$, gives the per cent of variance in $\mathrm{X}_{\mathrm{o}}$, which is added to predictability when the $\mathbf{R}_{\mathrm{c}}$ levels are added to an equation that already contains the feature measures as predictors. This value is .011 and .021 for the first and second administration, respectively. Similarly, $\mathrm{r}_{0.1-10}^{2}-\mathrm{r}_{0.1-3}^{2}$ measures the increase in prediction that occurs when the feature measures are added to an equation that already includes $\mathbf{R}_{c}$ levels as predictors. This value is .214 and .149 for administrations 1 and 2 , respectively. Clearly, then, knowledge of the $\mathbf{R}_{\mathrm{c}}$ level adds little to predictability when the magnitude of the features has been specified, while the converse is not true. Finally, it is worth noting that high levels of prediction were achieved from feature measures within each $R_{c}$ level.

\section{STUDY 2}

Previous work with polygons has demonstrated that discrimination performance can be psychophysically related to feature measures when discrimination latency (Brown \& Behrman, 1968) and discrimination in the presence of visual noise (Aiken \& Brown, 1969a, b, c) are spatially analyzed. Evans and his coworkers (e.g., Evans, 1967a, b; Walker \& Evans, 1967) have discussed the effect of varying the statistical structure of sets of patterns upon discrimination difficulty. It has been argued that $\mathbf{R}_{c}$ and discriminability are inversely related since higher levels of $R_{c}$ reduces variability of properties that provide the basis for distinguishing among individual patterns. This second study was designed to test the effect of $\mathbf{R}_{\mathbf{c}}$ upon discrimination difficulty with both polygons and histoforms and to evaluate the power of $\mathbf{R}_{c}$ and feature measures as predictors of discrimination difficulty.

Table 2

Summary of Relationships Between $\mathbf{R}_{c}$ Levels and Feature Measure Distributions

\begin{tabular}{|c|c|c|c|c|c|c|c|c|c|c|c|c|}
\hline \multirow[b]{2}{*}{ Measures } & \multicolumn{4}{|c|}{ Correlations } & \multicolumn{4}{|c|}{ Means } & \multicolumn{4}{|c|}{ Standard Deviations } \\
\hline & $\mathbf{R}_{\mathbf{c}}$ & 0 & 40 & 70 & $\mathbf{R}_{\mathbf{c}}$ & 0 & 40 & 70 & $\mathbf{R}_{\mathbf{c}}$ & 0 & 40 & 70 \\
\hline $\begin{array}{l}1 \\
2 \\
3 \\
4 \\
5 \\
6 \\
7\end{array}$ & & $\begin{array}{r}56 \\
-10 \\
-41 \\
70 \\
60 \\
59 \\
66\end{array}$ & $\begin{array}{r}-16 \\
-04 \\
22 \\
-30 \\
-24 \\
-25 \\
-18\end{array}$ & $\begin{array}{r}-40 \\
13 \\
18 \\
-39 \\
-35 \\
-34 \\
-48\end{array}$ & & $\begin{array}{r}4478.84 \\
61.80 \\
57.93 \\
126.54 \\
62.85 \\
42.19 \\
111.58\end{array}$ & $\begin{array}{r}2042.79 \\
61.75 \\
60.87 \\
24.79 \\
20.02 \\
10.87 \\
82.10\end{array}$ & $\begin{array}{r}1182.16 \\
62.56 \\
60.69 \\
15.74 \\
14.38 \\
7.47 \\
71.38\end{array}$ & & $\begin{array}{r}2761.14 \\
4.86 \\
4.74 \\
85.86 \\
45.75 \\
35.48 \\
25.19\end{array}$ & $\begin{array}{r}1632.84 \\
3.05 \\
2.83 \\
14.87 \\
11.36 \\
6.67 \\
10.28\end{array}$ & $\begin{array}{r}1371.40 \\
1.65 \\
1.57 \\
5.82 \\
5.03 \\
4.49 \\
16.06\end{array}$ \\
\hline
\end{tabular}


Table 3

Summary of $\mathbf{R}_{\mathrm{c}}$ Levels and Feature Measures as Predictiors of Reproduction Errors

\begin{tabular}{lcc} 
& \multicolumn{2}{c}{ Administration } \\
Predictors & 1 & 2 \\
\hline Over $\mathbf{R}_{\mathrm{c}}$ Levels $(\mathrm{N}=60)$ & & .109 \\
$\mathbf{R}_{\mathrm{c}}$ Levels $\left(\mathrm{X}_{1}-\mathrm{X}_{3}\right)$ & .139 & .237 \\
$\left.\mathrm{Feature} \mathrm{Measures} \mathrm{X}_{4}-\mathrm{X}_{10}\right)$ & .342 & .258 \\
$\mathrm{X}_{1}-\mathrm{X}_{10}$ & .353 & \\
Within $\mathbf{R}_{\mathrm{c}}$ Levels $(\mathrm{N}=20)$ & & .392 \\
$\mathbf{R}_{\mathrm{c}}=.00$ & .486 & .652 \\
$\mathbf{R}_{\mathrm{c}}=.40$ & .330 & .786 \\
$\mathbf{R}_{\mathrm{c}}=.70$ & .531 & \\
\hline
\end{tabular}

Table 4

Mean Latency (Seconds) Over Twenty Forms and Eight Subjects for the Twelve Experimental Conditions

\section{Administration}

\begin{tabular}{ccccc} 
& \multicolumn{2}{c}{1} & \multicolumn{2}{c}{$\frac{2}{2}$} \\
\cline { 5 - 5 } Constraint & Polygones & Histoforms & Polygons & Histoforms \\
\hline $0 \%$ & 4.34 & 8.87 & 3.59 & 7.61 \\
$40 \%$ & 6.16 & 9.54 & 4.77 & 7.46 \\
$70 \%$ & 9.92 & 11.21 & 8.51 & 10.44 \\
\hline
\end{tabular}

Table 5

S Summary of $R_{c}$ Level and Feature Measures as Predictors of Discrimination Latency

\begin{tabular}{|c|c|c|}
\hline \multirow[b]{2}{*}{ Predictors } & \multicolumn{2}{|c|}{ Administration } \\
\hline & 1 & 2 \\
\hline $\begin{array}{l}\text { Over } R_{\hat{f}} \text { Levels }(\mathrm{N}=60) \\
\mathbf{R}_{c} \text { Levels }\left(\mathrm{X}_{1}-\mathrm{X}_{3}\right) \\
\text { Feature Measures }\left(\mathrm{X}_{4}-\mathrm{X}_{10}\right) \\
\mathrm{X}_{1}-\mathrm{X}_{10}\end{array}$ & $\begin{array}{l}.340 \\
.427 \\
.472\end{array}$ & $\begin{array}{l}.267 \\
.383 \\
.422\end{array}$ \\
\hline $\begin{array}{l}\text { Within } \mathbf{R}_{\mathrm{c}} \text { Levels }(\mathbf{N}=20) \\
\mathbf{R}_{\mathrm{c}}=0 \\
\mathbf{R}_{\mathrm{c}}=.40 \\
\mathbf{R}_{\mathrm{c}}=.70\end{array}$ & $\begin{array}{l}.419 \\
.594 \\
.751 \\
\end{array}$ & $\begin{array}{l}.304 \\
.453 \\
.803 \\
\end{array}$ \\
\hline
\end{tabular}

\section{Method}

Patterns. The patterns used in Study 1 were also used in this study.

Subjects. Eight undergraduate students served as Ss.

Procedure and design. A total of 240 problems was constructed with 20 problems for histoforms and polygons at each level of $R_{c}$. Each problem was constructed by photographing one of the patterns in the center of a display with all 20 patterns in that condition arranged in randomly selected positions on a square. Each pattern served as the "correct" pattern in one problem.

On each trial, a ready light indicated to $S$ that the trial was started, $S$ depressed a foot pedal to present the slide from a random-access slide projector, the slide was back projected on a screen, and the $S$ made his choice by pressing a key. A timer recorded discrimination latency as the time between display onset and the S's key press. Following the key press, $S$ indicated verbally the position in which the correct choice had appeared. Ss were instructed to respond as rapidly as possible, but to avoid errors. Errors were very rare, but when an error was made that trial was repeated at a randomly selected position later in the sequence. Ss were tested individually in 60 to $70-\mathrm{min}$ sessions.

For each $S$, the sequence of constraint levels, pattern types, and problems within each of the other two conditions was independently randomized. The entire session was repeated in a second administration after an interval of $24-48 \mathrm{~h}$.

\section{Results}

Table 4 shows the mean latency for the 12 experimental conditions. An analysis of variance of these data, assuming all factors fixed, showed that polygons were more difficult to discriminate than histoforms $(p \leqslant .01)$, and discrimination difficulty increased with $R_{c}(p \leqslant .01)$, but the two administrations were of equal difficulty $(p \geqslant .05) . \mathbf{R}_{c}$ did interact significantly with type of pattern $(p \leqslant .01)$, and this interaction was due to a greater effect of $R_{c}$ on polygons than on histoforms. Subsequent comparisons among means showed that latencies were different among all levels of $\mathbf{R}_{c}$ when polygons were liscriminated ( $p \leqslant .01$ ), but mean latency for $R_{c}=40 \%$ and $R_{c}=70 \%$ were not different for histoforms $(p \geqslant .05)$. The reliability coefficient, computed over the 60 problems and between mean latencies for the two administrations, was .89 .

Regression analyses, predicting mean latency, are summarized in Table 5 where the squared multiple correlations are presented for the same regression analyses as were used in Study 1 to predict reproduction errors. It is worth noting that all multiple correlations were substantial and that feature measures predicted a relatively large proportion of latency variance within each level of $\mathbf{R}_{c}$. As was the case with reproduction errors, adding $\mathbf{R}_{c}$ levels to feature measures as predictors $\left(r_{0.1-10}^{2}-r_{0.4-10}^{2}=.045\right.$ in administration 1 and .039 in administration 2) added little to prediction. Adding features to $\mathbf{R}_{\mathrm{c}}$ levels as predictors, however, increased the proportion of predictable variance by $13.2 \%$ in the first administration and by $15.5 \%$ in the second administration.

\section{DISCUSSION}

These results are in agreement with two sets of studies that have been concerned with the development of quantification procedures for the analysis of visual pattern perception. One approach, which has evolved out of information analysis and is exemplified by the current work of Evans (e.g., 1967a, b) has shown that constraint redundancy is inversely related to discriminability and directly related to reproduction accuracy when histoforms are used as patterns. These data show the same general results when both histoforms and polygons are quantified by the same procedures. Our work has been based upon the assumption that Ss abstract particular features of patterns the magnitudes of which serve to determine perceptual performance. It has been possible to account for considerable variance in similarity judgments (Behrman \& Brown, 1967), discrimination latency (Brown \& Andrews, 1967), discrimination in thy presence of visual noise (Aiken \& Brown, 1969a, b, c), and visual and tactual complexity ratings (Brown \& Behrman, 1968) from knowledge of pattern features. Similar results have been obtained by others (e.g., Stenson, 1968). While there are task-specific differences (Aiken \& Brown, 1969b, c; Fenker \& Brown, in press), there is considerable similarity in the set of pattern measures that covary with performance in a variety of tasks.

In these studies, we have combined these two approaches to quantification of visual patterns with a common stimulus domain. While the results show the predicted results of quantifying characteristics of sets of patterns, $\left(R_{c}\right)$, superior prediction occurs when the magnitudes of particular measures are used. This suggests that the effect of $\mathbf{R}_{c}$ upon perception is mediated through changes in the statistical structure of the cue-dimension space. Since the linear regression techniques used in these studies assume a simple additive model for how information about each cue dimension is combined into a unitary response, additional work is called for in which various models for this process are evaluated. 


\section{REFERENCES}

AIKEN, L. S., \& BROWN, D. R. A spatial analysis of the discriminability of forms in noise. Perception \& Psychophysics, 1969a, 5, 171-175.

AIKEN, L. S., \& BROWN, D. R. Visual form perception: Congruence among spatial configurations. Perception \& Psychophysics, 1969b, 5, 155-160.

AIKEN, L. S., \& BROWN, D. R. Visual form perception: Task demands and congruence among spatial solutions. Psychonomic Science, 1969c, $15,219-220$.

ATTNEAVE, F., \& ARNOULT, M. D. The quantitative study of shape and pattern perception. Psychological Bulletin, 1956, 53, 45 2-471.

BEACH, L. R. Cue probabilism and inference behavior. Psychological Monographs, 1964a, 78 (Whole No. 582).

BEACH, L. R. Recognition, assimilation, and identification of objects. Psychological Monographs, 1964b, 78 (Whole No. 583).

BEHRMAN, B. W., \& BROWN, D. R. Multidimensional scaling of form: A psychophysical analysis. Perception \& Psychophysics, 1968, 4, 19-25.

BROWN, D. R., \& ANDREWS, M. H. Visual form discrimination: Multidimensional analyses. Perception \& Psychophysics, 1968, 3, 401-406.

BROWN, D. R., \& BRUMAGHIM, S. H. Perceptual equivalence, pattern perception, and multidimensional methods. Perception \& Psychophysics, $1968,4,253-256$.

BROWN, D. R., \& OWEN, D. H. The matrices of visual form: Methodological dyspepsia. Psychological Bulletin, 1967, 68, 243-259.

BRUMAGHIM, S. H., \& BROWN, D. R. Perceptual equivalence between visual and tactual pattern perception: An anchoring study. Perception \& Psychophysics, 1968, 4, 175-179.

EDMONDS, E. N., \& EVANS, S. H. Prediction of schema learning by linear regression. Psychonomic Science, 1966a, 5, 457-458.

EDMONDS, E. M., \& EVANS, S. H. Schema learning without a prototype. Psychonomic Science, 1966b, 5, 247-248.

EDMONDS, E. M., \& MUELLER, M. R. The role of schemata in perceptual learning. Psychonomic Science, 1967, 8, 239-240.

EVANS, S. H. Redundancy as a variable in pattern perception. Psychological Bulletin, 1967a, 67, 104-113.

EVANS, S. H. A brief statement of schema theory. Psychonomic Science, $1967 b, 8,87-88$.

EVANS, S. H., \& MUELLER, M. R. VARGUS 9: Computer stimuli for schema research. Psychonomic Science, 1966, 6, 511-512.

FENKER, R. M., Jr., \& BROWN, D. R. Pattern perception, conceptual spaces, and dimensional limitations on information processing. Multivariate Behavioral Research, in press.

FORSYTH, G. A., \& BROWN, D. R. Stimulus correlates of tachistoscopic discrimination-recognition performance: Compactness, jaggedness, and areal asymmetry. Perception \& Psychophysics, 1967, 2, 597-600.
FORSYTH, G. A., \& BROWN, D. R. Stimulus recognizability judgments as a function of the utility of physical dimensions in recognitiondiscrimination problems. Perception \& Psychophysics, 1968, 3, 85-88.

HUBEL, D. H., \& WEISEL, T. N. Receptive fields, binocular interaction, and functional architecture in the cat's visual cortex. In R. N. Haber (Ed.), Contemporary theory and research in visual perception. New York: Holt, Rinehart \& Winston, 1958. Pp. 150-166.

STENSON, H. H. The psychophysical dimensions of similarity among random shapes. Perception \& Psychophysics, 1968, 3, 201-214.

STERNBERG, $S$. Two operations in character recognition: Some evidence from reaction-time measurements. Perception \& Psychophysics, 1967, 2, 45-53.

THURMOND, J. B., \& ALLUISI, E. A. An extension of the information deductive analysis of form. Psychonomic Science, 1967, 7, 157-158.

WALKER, D. W., \& EVANS, S. H. Visual pattern recognition as a function of schematic redundancy, stimulus channel capacity, and stimulus exposure time. Paper presented at the Psychonomic Society Convention, 1967.

WINER, B. J. Statistical principles in experimental design. New York: McGraw-Hill, 1962

\section{NOTES}

1. This research was supported by Research Grant HD-00909 from the National Institute of Child Health and Human Development.

2. Address: Department of Psychology, Purdue University, Lafayette, Indiana 47907.

3. We gratefully acknowledge the assistance of Dr. Selby Evans, Texas Christian University, who provided these patterns under a program of research supported in part by a Department of Defense Project THEMIS, Contract No. DAADOS-68-C-D176.

4. Measures of patterns used were (for more detailed information, see Brown \& Owen, 1967): (1) Variance of interior angles. This measure is the second central moment of the size, in degrees, of all interior angles of the polygons and perceptually reflects the degree of "jaggedness" of the pattern. (2) Mean of the $X$ coordinates. This measures skewness of the area with regard to the $X$ axis. (3) Mean of the $Y$ coordinates. A measure of skewness of area with regard to the $Y$ axis. (4) Second moment of the deviation of side length from that of a regular polygon with the same area. Perceptually this measures the combined effects of dispersion of area and of variability of angle sizes. (5) Variance of side lengths. (6) Largest radial length. This is the length of the longest radius from the area center of gravity to the perimeter of the pattern. It reflects "elongation." (7) Perimeter length. Perimeter length reflects both "jaggedness" and dispersion of area.

(Accepted for publication A pril 4, 1969.) 